\title{
O espaco das Conferências Intepnacionais de Educação (CIES) da OIE/Unesco e o processo de políticas públicas educativas
}

Elisabete Cristina

Cruvello da Silveira

Palavras-chave: contexto

internacional; políticas

públicas e educação;

conferências internacionais.

Analisa o espaço das Conferências Internacionais de Educação (CIEs) organizadas pelo Escritório Internacional de Educação (OIE) da Unesco e sua relação com o processo de elaboração de políticas públicas na década de 90. Duas questões fundamentais orientaram o artigo: 1) como pode ser definido 0 espaço das CIEs nos anos 90 e 2) como os processos de globalização e interdependência influenciaram essas conferências. As CIEs foram definidas como um espaço de articulação internacional de relações de poder e de debate sobre as linhas de políticas educativas de dimensões contraditórias. Além disso, foi relevante delimitar dois tipos de conferências: estratégica e protocolar. No caso das CIEs realizadas nos anos 90, o tipo progressivamente predominante é o estratégico, não obstante ainda coexistam práticas rotineiras $\mathrm{e}$ protocolares.

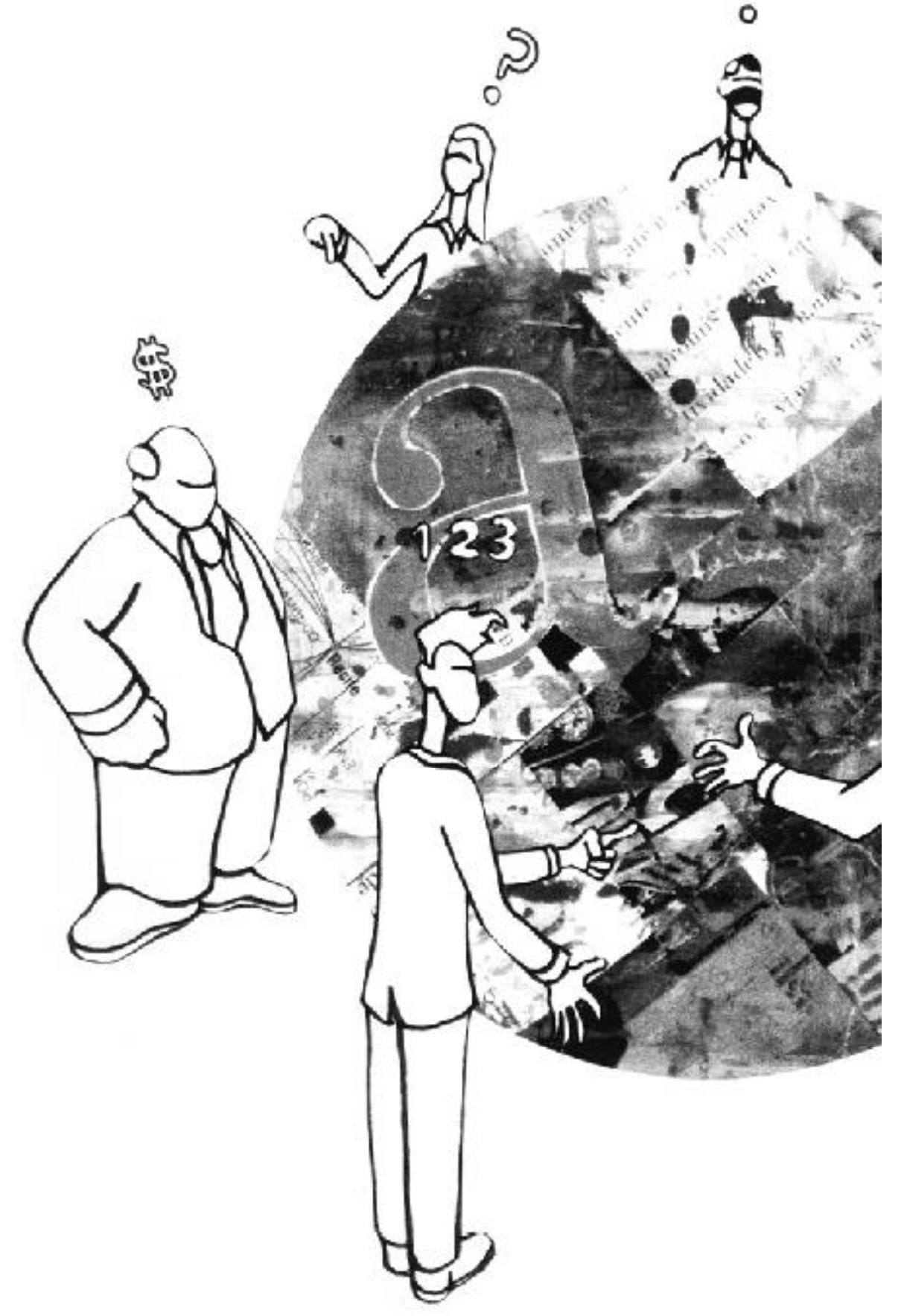


블

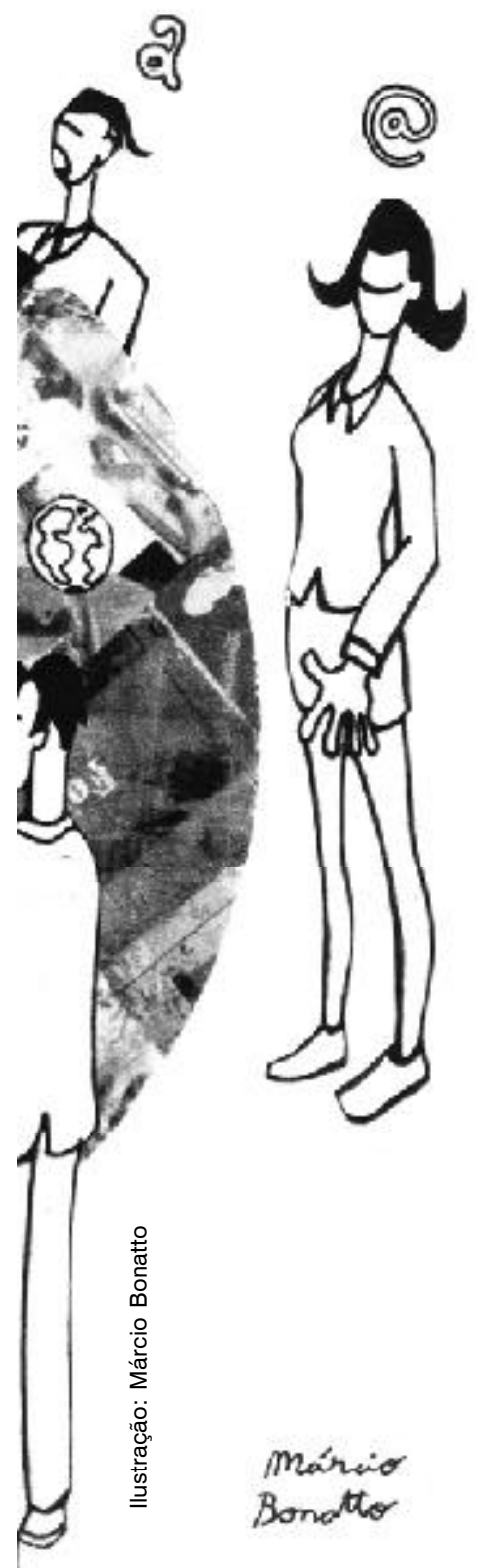

\section{Introdução}

Ao longo da década de 90, alguns analistas têm questionado a presença marcante dos organismos internacionais, sobretudo organismos de financiamento como o Banco Mundial (BM) e o Banco Interamericano de Desenvolvimento (BID), quanto ao processo de elaboração de políticas públicas nos países latino-americanos. No entanto, pouco se tem refletido sobre o papel das reuniões de cúpula ou sobre as conferências internacionais realizadas abordando temas diversos da agenda pública, como, por exemplo, as conferências patrocinadas pela Organização das Nações Unidas (ONU) e suas respectivas agências multilaterais, como a Organização das Nações Unidas para a Educação, a Ciência e a Cultura (Unesco).

Além disso, segundo alguns analistas, os processos de progressiva globalização e interdependência têm provocado a discussão em conjunto de vários problemas mundiais, cuja conseqüência vem sendo o debate, cada vez mais freqüente como também acentuado, pelos foros internacionais, sobre a definição das linhas comuns de ação política para os países. Nesse contexto, algumas questões se fazem pertinentes: Para que servem as conferências? Como se organizam? Que tipos de procedimentos adotam? Qual o impacto das recomendações estabelecidas nessas reuniões para o processo de elaboração de políticas públicas? Como o recente contexto internacional vem influenciando essas conferências em sua totalidade?

Discutir a lógica presente nessas reuniões internacionais possibilita não somente melhorar a qualidade do conteúdo das respostas acerca dos problemas analisados, mas, sobretudo, questionar seu papel para o processo de elaboração de políticas públicas em tempos da chamada "era da globalização e interdependência".

\section{Características do contexto internacional dos anos 90}

Antes de iniciar, de fato, a apresentação das principais características, torna-se relevante definir o processo de globalização que constitui o contexto internacional no qual se inserem as conferências ou reuniões de cúpula. De acordo com a visão dos analistas consultados, globalização significa não só um processo de intensificação das relações sociais em escala mundial, como também estabelece um desenvolvimento desigual que tanto fragmenta quanto coordena, introduzindo, portanto, novas formas de interdependência mundial.

Assim, esta definição dialética do processo de globalização como um movimento econômico e político, que integra e desintegra, também permite delimitar de forma peculiar o espaço de uma conferência internacional.

Uma conferência ou reunião internacional patrocinada por um organismo internacional constitui um espaço de articulação e de relações de poder entre Estados sobre as orientações de políticas de dimensões contraditórias. Por um lado, este espaço determina que se estabeleçam grandes consensos em torno das tendências das linhas de políticas públicas. Não obstante, por outro lado, ocorrem nele algumas práticas que são cumpridas rotineira e protocolarmente, estabelecendo assim uma relação formal $e$ peculiar entre as recomendações aprovadas pelos atores na conferência e pelo processo de decisão de uma política pública em cada contexto nacional.

A partir dessas definições básicas, é necessário traçar um conjunto de características articuladas entre si sobre o contexto das relações internacionais dos anos 90 e suas vinculações com a lógica das conferências internacionais, isto é: Quais são as características que distinguem o atual contexto internacional dos anteriores, gerando um maior interesse dos organismos internacionais, países-membros e outros atores em relação ao espaço das conferências mundiais? O que se pode apreciar de "novo" nas tendências da ordem mundial emergente? 
Segundo os teóricos das relações internacionais, as "novas" estratégias de interdependência mundial têm gerado um maior interesse dos organismos internacionais, países-membros e outros atores no que se refere à contribuição das reuniões de cúpula internacionais para o processo de elaboração de políticas públicas em cada contexto nacional. Dessa forma, as principais características sobre o "novo" contexto internacional serão explicitadas de forma sintética a seguir.

A primeira característica diz respeito à tensão entre a realidade vigente e o marco jurídico internacional que rege os organismos internacionais, ou seja, existe uma inadaptação real entre o marco que regulamenta as instituições internacionais e as demandas e as tendências atuais do contexto internacional. Segundo o Direito Internacional, o conceito de organismo internacional ainda vigente sublinha uma composição essencialmente interestatal, dotada de autonomia jurídica, com base jurídica convencional e estrutura permanente. Contudo, segundo os analistas, este conceito de organização internacional não serve mais para uma "sociedade global" e sua reorientação jurídica se tornou urgente e consensual.

Essa tensão tem engendrado no seio da Unesco e de seus escritórios técnicos um processo paulatino de reorientação e reestruturação das estratégias e mecanismos de relacionamento não só com os Estados-membros, mas também com outras organizações do sistema das Nações Unidas e outras agências.

A segunda característica do contexto internacional é que ele se encontra fortemente marcado pela globalização e interdependência, deixando de ser exclusivamente interestatal e centrado no Estado. Neste caso, a multiplicação de atores nãoestatais em escala mundial e global, como as multinacionais e seus interesses, o lobby das embaixadas e das chancelarias, além de algumas organizações não-governamentais. No âmbito das CIEs esta característica manifestou-se a partir do maior envolvimento de outros participantes tais como membros das organizações não-governamentais (ONGs), representantes dos organismos internacionais e especialistas do Ministério da Educação em vez dos expertos do Ministério das Relações Exteriores que costumavam participar com mais freqüência das conferências nos anos 80 .
A terceira característica diz respeito ao concertamento político como estratégia ou estilo de negociação e consulta nos anos $90 \mathrm{em}$ relação às décadas anteriores que se fundamentavam basicamente em uma estrutura de poder bipolar, ou seja, durante o período considerado de guerra fria, o poder residia no equilíbrio estratégico das chamadas grandes potências (Estados Unidos e ex-União Soviética). Com o fim da guerra fria, a "ordem mundial emergente" tem valorizado a busca de consenso e a negociação mais interdependente, enquanto o poder ficou menos transferível, tangível e coercitivo.

É conveniente lembrar que todo processo de negociação reside numa relação social de poder como intercâmbio que exprime uma dimensão de conflitos e resistências, para que se obtenha o acordo. Neste contexto, outros fatores se tornaram mais relevantes no seio das $\mathrm{CIEs}$, tais como a educação, o desenvolvimento tecnológico e, especialmente, as fontes de poder: a informação, a capacidade de negociação e de estabelecimento de alianças.

A quarta característica articulada à anterior se refere ao fato de que o poder no atual contexto está mais fundamentado na informação, no conhecimento e na competitividade econômica do que no emprego dos métodos tradicionais de poder mais fundamentados no uso da força militar e na coerção, vigentes nas décadas anteriores. Neste sentido, cabe conceituar a "relação de poder" como uma relação de intercâmbio, em que o poder reside na margem de liberdade que disponha cada um dos atores comprometidos, em face da sua maior ou menor capacidade e possibilidade de recusar o que o outro lhe pede ou incidir no curso de suas ações ou decisões.

Sobre essa característica, duas posturas foram encorajadas ao longo dos anos 90: por um lado, um investimento mais acentuado na capacidade de cada Estadomembro, no sentido de que produzisse informações e análises a respeito dos temas de convocatória da conferência e, por outro, um contexto preparatório para as conferências que refletisse mais efetivamente um intercâmbio entre os distintos participantes e não tanto uma imposição dos técnicos do organismo internacional.

A quinta característica ressalta que muitos problemas dos anos 90 são conceituados como globais e comuns ao conjunto dos 
países, o que demanda, também, a análise conjugada por distintos atores nas reuniões internacionais. A este respeito os temas de convocatória das reuniões da ONU anunciam uma reorientação de seu foco: na década de 90 , os chamados "novos temas" ou "temas globais da agenda multilateral das Nações Unidas" trataram especialmente dos direitos humanos, políticos e cívicos; do meio ambiente; da população; do combate ao narcotráfico e de outras questões de caráter social. Em relação às décadas anteriores, as convocatórias da ONU se vinculavam, sobretudo, ao tema do desarmamento militar e do desenvolvimento socioeconômico dos países do Terceiro Mundo.

Os temas da agenda convocatória das CIEs não são livres ou neutros, pois geralmente o seu controle dispõe de um recurso político decisivo a quem o detenha, que no caso é a conferência geral da Unesco. Neste sentido, os temas tratados, freqüentemente, tiveram relação com o contexto de globalização e interdependência e foram: Educação para Todos (1990), Educação e Cultura (1992), Educação para o Entendimento Internacional (1994), Formação de Professores em um Mundo de Mudança (1996).

Outros eventos ocorridos no contexto da política mundial e que marcaram a configuração de outro balanço de poder pertinente às reuniões internacionais foram: a queda do muro de Berlim; as mudanças radicais da sociedade soviética nos planos econômico, político e sociocultural; o processo eleitoral democrático em todos os países socialistas e do leste europeu; a extinção do Pacto de Varsóvia; a reunificação da Alemanha e o seu conseqüente destaque nos assuntos europeus e mundiais; o processo de independência da Lituânia, Letônia e Estônia; a crise do comunismo como sistema de referência e o questionamento sobre o papel da Organização do Tratado do Atlântico Norte (Otan).

Estas características do contexto internacional constituem o pano de fundo para discutir a pertinência efetiva do espaço das conferências internacionais realizadas pelos organismos internacionais ao longo dos anos 90 e, especificamente, as reuniões de cúpula promovidas pelo Escritório Internacional de Educação (OIE), da Unesco, em Genebra, Suíça, e que são o tema deste artigo.

\section{Revendo 0 espaço das CIES da OIE/Unesco nos anos 90}

As CIEs são encaradas como um espaço técnico-político, uma vez que nessas reuniões se vêm definindo as linhas-mestras da política educativa em nível mundial e que se expressam mediante as recomendações aprovadas pelos Estados-membros e demais participantes. Neste sentido, configura-se uma peculiar relação interestatal de poder, caracterizada pela capacidade de o conjunto de atores estatais aprovar recomendações, propostas e sugestões para as linhas de políticas educativas, não se referindo, portanto, ao momento de tomada de decisão do Estado e da implementação de uma política pública no contexto nacional.

Segundo o documento da Unesco de 1987, as CIEs "significam um lugar de encontro, intercâmbio de idéias e concertamento, para definir as orientações e soluções para os grandes problemas da educação" (Unesco, 1987, p. 45). Portanto, não obstante as CIEs não terem a condição de afetar tão diretamente o processo de definição e implementação da política pública de cada contexto nacional, contribuem no sentido de apontar e sublinhar os caminhos a serem seguidos. Vale a pena reconstruir algumas concepções sobre o espaço das CIEs enfatizadas por participantes dessas conferências, entrevistados na pesquisa realizada como dissertação de mestrado que resultou neste artigo (Silveira, 1998, p. 87-89):

1) ampliam a visão conceitual necessária ao processo de tomada de decisões, constituindo-se um espaço de reflexão sobre novas temáticas;

2) aprovam recomendações que procuram guiar as políticas, enquanto a relevância dessas recomendações consiste em que elas sejam geradas a partir da formação de consensos resultantes de um processo anterior ao da conferência em si mesma, ou seja, do contexto preparatório que costuma anteceder a realização da conferência;

3) aprovam linhas para a cooperação internacional, que em geral costuma ser mais importante do que o mero cumprimento protocolar das recomendações, pois esta cooperação internacional visa colocar em prática efetivamente os processos de reforma educativa; 


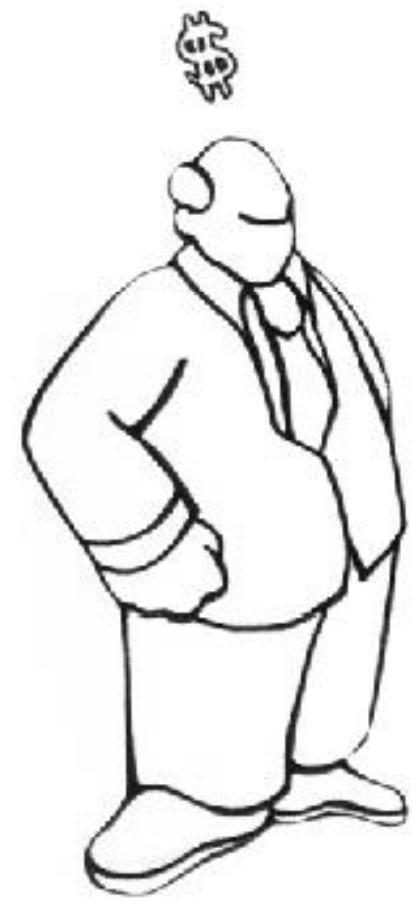

4) possibilitam a comparação e a sistematização de diferentes experiências educativas colocadas em prática em âmbito mundial;

5) possibilitam um momento de diálogo e intercâmbio entre autoridades, como os ministros de Educação e os representantes dos organismos internacionais.

Tendo em consideração essas finalidades e seu impacto no processo de elaboração de políticas, duas reflexões básicas merecem ser destacadas:

a) Não obstante, freqüentemente, os Estados-membros ratifiquem as recomendações, as mesmas desempenham uma força peculiar, muitas vezes indireta e formal, nas decisões das políticas nacionais, pois a elaboração de políticas públicas implica um intrincado processo que se inicia com a identificação de problemas, sua definição como questão pública, seu ingresso na agenda de decisões mediante um complexo jogo de vários atores públicos e privados, até por fim culminar em uma decisão política. No caso específico das recomendações do Escritório Internacional de Educação, da Unesco, constata-se uma relação de poder, como intercâmbio, que perpassa mais fortemente a contribuição estratégica e técnica, do que recursos e condicionamentos financeiros, como costuma ocorrer nos acordos de cooperação internacional com os organismos internacionais de financiamento.
Nos anos 90, a contribuição que a Unesco, como organismo internacional, efetivou foi mais no nível do poder derivado da informação e do conhecimento dos intelectuais e especialistas no âmbito das reuniões de cúpula, como, por exemplo, na definição dos temas de agenda internacional ou na preparação dos documentos e da estrutura das conferências. Conhecimento para a ação é o modelo desenvolvido pelos expertos no sentido de valorizar o processo de busca e sistematização de informação sobre as tendências das políticas públicas, buscando ainda negociar e persuadir o político da relevância de seu conhecimento e sua projeção.

b) Diante disso, fica explícito que o propósito de uma conferência como a CIE é possibilitar um espaço estratégico de intercâmbio de experiências, estabelecendo amplos consensos a respeito das tendências e das linhas de políticas educativas. Neste caso, cabe especificar a natureza e a importância dos consensos nos anos 90 .

Em primeiro lugar, a formação de consensos, no contexto de uma conferência, tem origem, sobretudo, quando se consideram os conflitos, as diferenças de opiniões e as resistências. Na verdade, não significa que uma reunião de cúpula mundial seja um espaço neutro, uniforme, onde prevalecem a coesão e a harmonia. Em contraposição, para colocar-se de acordo, com freqüência se adota uma estratégia de negociação, onde o concertamento cria um mecanismo através do qual esses conflitos e tensões são resolvidos pelo diálogo, pela mediação e pelo acordo.

O contexto preparatório de uma conferência, por exemplo, poderia constituirse em um espaço fundamental como mecanismo para gerar amplos consensos sobre as linhas de políticas educativas, desde que houvesse uma participação de distintos atores da sociedade civil, como os do âmbito universitário e das organizações não-governamentais.

Em segundo lugar, basicamente, o contexto preparatório de uma conferência tem servido como estratégia que possibilita, por um lado, a elaboração de documentos mais sólidos para o debate na conferência e, por outro, permite também uma linha de avanço em relação ao tema amplo da convocatória. Em geral, quando os documentos chegam à conferência já estão praticamente negociados quanto à sua 
concordância, e as divergências ocorrem somente em torno de temas como financiamento da educação e sua organização.

Segundo Meny e Thoening (1992, p. $115)$, "quase sempre o consenso não é total ou unânime, nem o conflito é geral ou irredutível. O conflito pode expressar-se em termos de interesses materiais, de privilégios sociais ou de influência política, porém manifesta-se ainda de forma mais normativa e intelectual".

Tomando em consideração estas reflexões sobre o espaço das ClEs, cabe indagar: na realidade, essas conferências são um fórum de intercâmbio e de negociação sobre as orientações para as políticas educativas, tal como sustentam as definições sobre o espaço das conferências pela Unesco e por outros analistas? Como foi que a rotina, a retórica, os processos protocolares, que costumam gerar a perda do processo de diálogo, incidiram nas CIEs? Neste sentido, faz-se necessário expor os dois tipos de conferências que analisam o espaço das CIEs nos anos 90.

\section{Tipos de conferência: estratégica ou protocolar?}

$\mathrm{Na}$ pesquisa realizada identificaramse que, em uma mesma reunião, coexistem ainda os dois tipos de conferências estratégica e protocolar, muito embora em proporções diferenciadas. Ambos os tipos relacionam-se com o contexto internacional, uma vez que o tipo estratégico vincula-se com um padrão dos anos 90 , enquanto o tipo protocolar com um modelo do contexto internacional dos períodos anteriores.

O modelo protocolar denota a presença excessiva dos discursos prolixos e da rotina na dinâmica da reunião e das formalidades e informações protocolares por parte de certos países-membros. Já o modelo de conferência estratégica sublinha a presença mais intensa de mecanismos de trabalho que permitam o intercâmbio, o diálogo e a negociação entre os países-membros participantes.

Não obstante o fato de que os procedimentos protocolares não sejam a tônica da conferência estratégica, na realidade, uma reunião de cúpula de ministros da Educação com a CIE exige sempre um certo cerimonial, uma certa formalidade, no que diz respeito ao alto nível dos personagens envolvidos: ministros de Educação, embaixadores ou representantes dos países-membros, organismos internacionais associados da ONU, acadêmicos, observadores e outros convidados. Este cerimonial, porém, indica apenas respeito às autoridades presentes.

No caso das CIEs realizadas nos anos 90, foi confirmado que o tipo progressivamente predominante é o estratégico, não obstante alguns países-membros ainda atuassem de modo rotineiro e protocolar. Ficou também constatado pela análise crítica dos relatórios finais das conferências das CIEs e pelas entrevistas realizadas com organizadores e participantes das CIEs da OIE/Unesco, que, na década de 80 , as CIEs realizadas caracterizavam-se como um exemplo de conferência protocolar. Estas duravam cerca de oito dias, eram bastante formais, com extensivos discursos de ministros após ministros, que falavam sobre seu próprio país ou liam os informes enviados à OIE.

Nos anos 90, este modelo protocolar foi gradualmente superado basicamente em virtude do seguinte argumento: as demandas impostas pelos processos de globalização e interdependência fizeram com que a OIE como escritório técnico da Unesco buscasse, conjuntamente com alguns países membros, uma reacomodação do espaço das CIEs no sentido de torná-lo mais estratégico.

Como exemplo das CIEs realizadas na década de 90, podemse mencionar as mudanças na estrutura organizativa das reuniões, de tal forma que se tentou produzir um espaço onde predominassem mais o diálogo e o debate do que os discursos vazios e formais, a valorização do contexto preparatório e da melhoria qualitativa dos conteúdos dos informes enviados pelos países. No caso

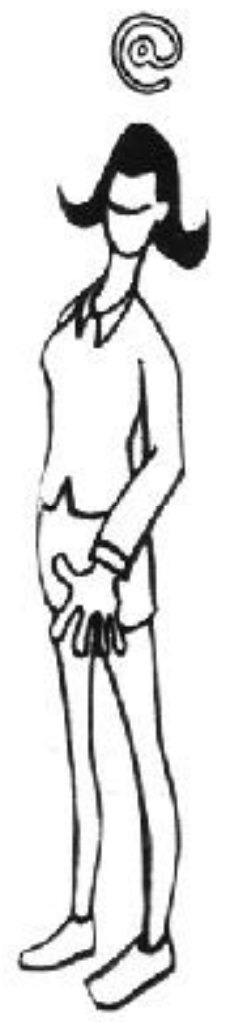


específico da estrutura organizativa nas reuniões dos anos 80 , costumavam-se tratar alguns temas em sessões plenárias $e$ outros em duas grandes comissões, o que foi paulatinamente alterado, ao longo dos anos 90 , para debates de estilo parlamentar organizados pelas entidades não-governamentais e por especialistas de alguns países-membros em parceria com os técnicos da OIE e de outros organismos internacionais.

Esta mudança na estrutura organizativa dos trabalhos visava, sobretudo, substituir a apresentação e leitura dos informes nacionais pelos representantes de cada país em apenas cinco minutos, já que permitia muito pouco intercâmbio e questionamento entre os 130 países que costumam participar das CIEs. A título de ilustração, na CIE de 1994, durante a reunião plenária, realizaram-se quatro grandes debates em estilo parlamentar e seis mesas-redondas sobre temas da convocatória, ao passo que na CIE de 1996 se introduziu uma pequena mudança: na plenária, dois grandes debates em estilo parlamentar e quatro mesasredondas sobre o tema da agenda.

Ao lado disso, segundo a análise interpretativa sustentada na minha dissertação da Faculdade Latino-Americana de Ciências Sociais (Flacso/Argentina), os países participantes das conferências foram classificados em três grupos específicos, examinados por um lado conforme 0 papel determinado pelo estatuto da OIE/ Unesco e, por outro, de acordo com a capacidade técnico-político-econômica de cada um deles. Os grupos são:

a) Estratégicos: formados por paísesmembros considerados influentes em função do seu potencial político-econômico e por sua participação no Conselho da OIE na última década e sua expressiva capacidade técnica na área da Educação. Neste contexto foram considerados: Japão, China e Índia (Ásia e Pacífico); Suíça, Canadá, Alemanha, França, Bélgica, Noruega e Espanha (Europa); Argentina, Brasil, Chile e México (América Latina). Com relação aos organismos internacionais, foram considerados os mais ligados ao tema da convocatória: Banco Mundial, Fundo das Nações Unidas para a Infância (Unicef), Programa das Nações Unidas para o Desenvolvimento (Pnud) e Organização Internacional do Trabalho (OIT). Em geral, estes organismos internacionais desempenham um papel mais ativo que os outros dois grupos classificados por meio da estratégia de negociação e da capacidade argumentativa acerca das propostas em debate.

b) Adjuntos: constituídos pelos demais Estados-membros que desempenham um papel secundário no fórum. Em primeiro lugar, aqueles que têm potencial políticoeconômico e capacidade técnica, embora sua participação nas conferências não tenha sido tão acentuada como a dos países sublinhados no grupo estratégico. Em segundo lugar, integram este grupo os países que têm direito a voto, a despeito de uma inexpressiva capacidade técnica e política, o que os leva a desempenhar, aí, um papel mais formal do que participativo. Em geral, sua participação ocorre em função da aprovação da proposta por meio do voto, já que no âmbito da CIE todos os países membros têm um voto de igual valor. Por fim, os organismos internacionais de menor peso para a temática do fórum e as organizações intergovernamentais que participam, pois celebraram acordos com a Unesco.

c) Espectadores: englobam os observadores, como as organizações não-governamentais e os jornalistas convidados. Eles possuem suas próprias posições, que podem estar de acordo com a proposta sustentada pelo fórum ou não, contudo costumam representar pouco em termos do processo de aprovação das propostas.

Cabe lembrar que esta classificação dos três grupos é bastante provisória, pois o país considerado adjunto poderá desempenhar um papel estratégico num futuro próximo, e isto também vale para os organismos internacionais e para o grupo considerado espectador. Segundo os analistas, a estrutura do sistema internacional encontra-se atualmente em processo de definição, o que poderá influir e alterar radicalmente esta proposta de classificação.

Assim, também no embate das forças, e no jogo das relações internacionais, pode-se esperar uma maior participação e envolvimento de novos protagonistas na preparação das conferências, tais como os professores universitários, além de membros de outras organizações não-governamentais que ainda não foram convidadas para as reuniões.

Por fim, é pertinente considerar o fator denominado "incrementalismo conservador", que expressa não só uma resistência 
ao processo de inovação por parte dos atores, como revela, também, uma nítida inclinação no sentido de que as mudanças estruturais se processem de forma bastante lenta no seio das conferências. O uso das práticas rotineiras, no entanto, e dos discursos protocolares, têm sido fortemente criticados pelos analistas nos anos 90, como forma de comportamentos a serem superadas.

Um outro aspecto que permite questionar com mais propriedade o espaço das CIEs refere-se à contribuição das recomendações aprovadas e como estas podem ser encaradas: uma aplicação direta e automática ou uma renovação de pactos anteriores, todavia, não colocados em prática? Como se pode compreender os vínculos entre as recomendações e o espaço das conferências? Esta é a discussão do próximotópico.

\section{Recomendação: aplicação linear ou renovação de pactos?}

Segundo a posição de Benedetto Conforti (1995, p. 188), "não se deve subestimar a importância da atividade das organizações internacionais, mesmo quando não se concretize em decisões vinculantes; o instrumento do qual se servem é a recomendação, que tem justamente o caráter de mera exortação".

Nesta passagem fica explícita, por um lado, a relação não vinculante das recomendações, pois sua natureza é de mera exortação ética. Por outro lado marca também o papel de sutil mediação dos escritórios técnicos dos organismos internacionais, tal como a OIE/Unesco, no sentido de fomentar as linhas de políticas educativas.

No caso concreto das CIEs da década de 90 , as recomendações aprovadas foram mais consideradas em termos de renovação de pactos anteriormente firmados do que de uma aplicação linear, como por exemplo:

1990: Educação para Todos - as recomendações fundamentavam-se nos pactos aprovados na Conferência de Jomtien, Tailândia;

1994: Educação para o Entendimento Internacional - atualizava as recomendações aprovadas na CIE de 1974 sobre a educação para a compreensão, a cooperação e a paz internacional e a educação relativa aos direitos humanos e às liberdades fundamentais;
1996: Formação de professores em um mundo de mudança - modernizava as recomendações relativas à condição do profissional docente de 1966, aprovadas em conjunto pela Unesco e OIT.

Nesse sentido, esse conjunto de recomendações ressalta duas idéias importantes: em primeiro lugar ratifica uma modernização das alianças firmadas anteriormente e em segundo lugar sublinha a especificidade do espaço das conferências, no sentido de enunciar a formação de amplos consensos sobre as tendências das linhas de políticas públicas. Cabe dizer ainda que a visão linear sobre a aplicação das recomendações tem sido revista em função de dois argumentos básicos:

$1^{\circ}$ argumento: se a recomendação aprovada na reunião é fruto de um contexto preparatório que promoveu reuniões regionais de consultas a fim de definir posições, intercambiar e solidificar argumentos, essa recomendação reflete e representa muito mais o processo que já está potencialmente em prática em vários países, do que a posição dos técnicos do organismo internacional.

$2^{\circ}$ argumento: o resultado ou a aplicação de uma recomendação está mais condicionado pela lógica do processo de decisão de políticas em um contexto nacional do que pela "boa intenção" dessas recomendações. Obviamente, o que diz ou afirma uma recomendação merece ser realizado concretamente, mas como reconheceu o documento da OIE/Unesco, "a aplicação da recomendação OITUnesco relativa à situação do pessoal docente tem sido mais difícil do que o previsto" (Unesco, 1996, p. 2).

$\mathrm{Na}$ realidade, as recomendações aprovadas como produto de uma reunião, como a da CIE, constituem uma orientação importante e mais uma contribuição que os Estados-membros podem contabilizar quanto aos processos de reformas educativas. Isto não significa que os países busquem sua aplicação ou desenvolvimento de forma automática ou linear, já que nos casos nacionais estas recomendações exercem um papel intermediário e peculiar no que se refere ao processo de tomada de decisão de políticas educativas. Em última análise, os responsáveis pelas decisões costumam considerá-las, mas, além disso, devem considerar, também, outras circunstâncias e fomentar alianças no âmbito de 
sua a própria realidade, para que se decida e implemente, de fato, uma política pública.

Cumpre aqui, conclusivamente, mencionar o papel das organizações não-governamentais como fator decisivo no processo de desenvolvimento das recomendações, como afirma esta declaração de um entrevistado para minha dissertação da Faculdade Latino-Americana de Ciências Sociais (Flacso/Argentina): "se a recomendação está fundamentada em um diagnóstico científico da realidade e a proposta é razoável, é certo que as mesmas associações nacionais e as organizações não-governamentais de um determinado país tomarão a defesa de sua aplicação" (Silveira, 1998, p. 143). Da mesma forma, é importante ressaltar que a influência das organizações não-governamentais varia de um país para outro e em relação aos temas de agenda pública. Sua função depende, assim, do marco regulamentar em cada país e da opinião pública tanto nacional quanto internacional.

\section{Considerações finais}

As reflexões sistematizadas neste artigo, sobre o espaço das CIEs da OIE/ Unesco e sua relação não só com o contexto internacional, como pano de fundo dessas reuniões de cúpula, mas também sua contribuição ao processo de elaboração de política pública, servem, com efeito, para questionar o papel das demais conferências patrocinadas por distintas oficinas técnicas dos organismos internacionais, permitindo indagar: 1) Como melhorar a qualidade das respostas ou das recomendações sobre os temas de convocatória no sentido de envolver outros participantes da sociedade civil? 2) Como estabelecer consensos, neste espaço, que representem efetivamente as demandas e as necessidades do conjunto da população e não apenas o resultado da posição de alguns especialistas do Ministério da Educação e dos organismos internacionais?

Segundo os analistas, o espaço das conferências internacionais merece ser melhor aproveitado do ponto de vista estratégico e não tanto protocolar, como aconteceu nas décadas anteriores, no sentido de buscar sua reacomodação entre as tendências do contexto internacional e entre as demandas de cada contexto nacional. Na realidade há uma lacuna no que diz respeito aos estudos que examinam com certa minuciosidade a real contribuição das conferências, pois, muitas vezes, eles tendem mais a contemplar e a realçar o papel da cooperação internacional via organismos internacionais, enquanto questionam muito pouco a concreta atuação das agências multilaterais como, por exemplo, a Unesco. Estas questões, com efeito, merecem ser objeto de melhor reflexão, a saber:

$\left.1^{\circ}\right)$ necessidade de maior articulação entre os temas de convocatória, os participantes, o contexto preparatório e a estrutura organizativa das conferências, a fim de possibilitar a construção de uma reunião mais estratégica do que protocolar;

$2^{\circ}$ ) necessidade de reflexão mais criteriosa a respeito dos mecanismos de negociação global para a criação de um espaço estratégico do ponto de vista do conjunto da sociedade civil;

$3^{\circ}$ ) necessidade de estudos críticos sobre a influência do contexto internacional para a organização de outras reuniões mundiais, estabelecendo algumas confrontações entre as mesmas.

$\mathrm{Se}$, de fato, a tendência para uma globalização crescente não só determina que os estados colaborem e tratem de modo conjunto questões e temas de agenda sobre os quais anteriormente tratavam de forma separada, é lícito esperar também que esta análise compartilhada, produzida nas reuniões mundiais, dê origem a grandes consensos em torno das linhas de políticas públicas. Assim, e desta forma, o espaço das diferentes conferências internacionais poderia receber maior atenção dos pesquisadores, dos políticos e dos demais componentes da sociedade civil. Afinal de contas, para que servem as conferências internacionais?

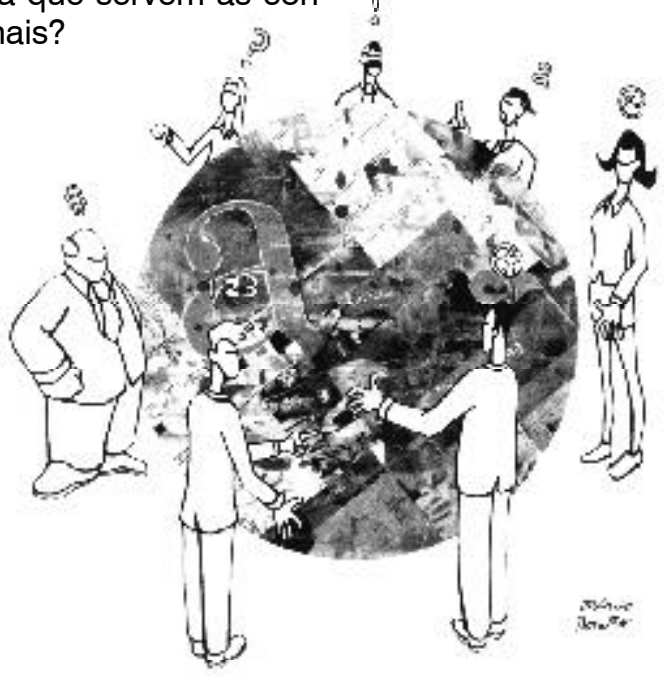

R. bras. Est. pedag., Brasília, v. 80, n. 196, p. 440-450, set./dez. 1999 


\section{Referências bibliográficas}

BRAILLARD, Phillpe. Teoria das relações internacionais. Lisboa: Fundação Calouste Gulbenkian, 1990.

CONFORTI, Benedetto. Derecho internacional. Buenos Aires: Zavalia, 1995.

CROZIER, Michel; RIEDBERG, Erhard. El actor y el sistema: las restricciones de la acción coletiva. México: Alianza Ed. Mexicana, 1990.

DE DROMI, Maria Laura San Martino. Integración iberoamericana: declaraciones de Guadalajara, Madrid, Salvador, Cartagena, Bariloche y Santiago. Buenos Aires: Ciudad Argentina, 1996.

FISHER, Roger. Más allá de Maquiavelo: herramientas para afrontar conflictos. Barcelona: Granica, 1996.

FREITAS JÚNIOR, Antônio Rodrigues. Globalização, Mercosul e crise do Estado-Nação: perspectivas para o direito numa sociedade em mudança. São Paulo: LTr, 1997.

GIDDENS, Anthony. As conseqüências da modernidade. São Paulo: Unesp, 1991

IANNI, Octavio. Teorias da globalização. Rio de Janeiro: Civilização Brasileira, 1991.

MARCOVITCH, Jacques (Org.). Cooperação internacional: estratégia e gestão. São Paulo: Edusp, 1994.

MENA KEIMER, Carlos Eduardo. Toma de decisiones y políticas: algunas aplicaciones a la política exterior. Buenos Aires: Grupo Ed. Latinoamericano, 1990.

MENY, Ives; THOENING, Jean-Claude. Las políticas educativas. Barcelona: Ariel, 1992.

NYE, Jospeh S. (Hijo). La naturaleza cambiante del poder norteamericano. Buenos Aires: Grupo Ed. Latinoamericano, 1986.

OSZLAK, Oscar. Teoría de la burocracia estatal. Barcelona: Paidós, 1984.

PELLICER, Olga (Comp.). Las Naciones Unidas hoy: visión de Mexico. México: Fondo de Cultura Económica, 1994.

SILVEIRA, Elisabete Cristina Cruvello. El rol de las Conferencias Internacionales de Educación y las políticas educativas en los años 90. Buenos Aires, 1998. Dissertação (Mestrado) - Faculdad Latinoamericana de Ciencias Sociales.

UNESCO. Informe final da Conferência Geral da Unesco. Paris, 1987.

Escritório Internacional de Educação. Informe preliminar da Conferência Internacional de Educação. Genebra, 1996.

Recebido em 15 de junho de 2000.

Elisabete Cristina Cruvello da Silveira, professora assistente do Departamento de Sociologia e Metodologia das Ciências Sociais da Universidade Federal Fluminense (UFF), é doutoranda da Faculdade de Filosofia e Letras da Universidade de Buenos Aires (Filo/UBA), Argentina. 


\section{Abstract}

It analyzes the space of summit meetings and the processes of definition of public educational policies. It is fundamental to mention that the International Conference on Education (ICE) are sponsored by the International Bureau of Education (IBE), which is a department of Unesco. Two guidelines were of main importance in the writing of this article: the dimension and scope of the ICEs in the nineties and the influence and repercussion of globalization in these meetings. The ICEs were defined as an international forum for discussion of diverse educational politics as well as a center comprised of both strategic and protocol-oriented conferences where we find power relations well represented. In the nineties, most ICEs were strategic rather than protocol-oriented.

Keywords: international context, public and education politics, international conferences. 